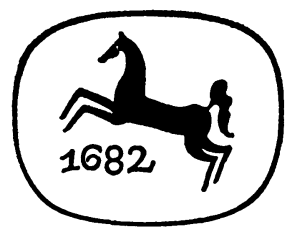

INDUSTRIELITERATUR DER DDR 


\section{Industrieliteratur der DDR}

Vom Helden der Arbeit zum

Planer und Leiter 
CIP-Kurztitelaufnahme der Deutschen Bibliothek

Zimmermann, Peter:

Industrieliteratur der DDR : vom Helden d.

Arbeit zum Planer und Leiter / Peter Zimmermann.

- Stuttgart: Metzler, 1984.

ISBN 978-3-476-00561-8

(Metzler-Studienausgabe)

ISBN 978-3-476-00561-8

ISBN 978-3-476-03200-3 (eBook)

DOI 10.1007/978-3-476-03200-3

(C) 1984 Springer-Verlag GmbH Deutschland

Ursprünglich erschienen bei J. B. Metzlersche Verlagsbuchhandlung und Carl Ernst Poeschel Verlag GmbH in Stuttgart 1984 


\section{INHALTSVERZEICHNIS}

I.Forschungslage und Konzeption der Untersuchung. ........... 1

1. Paradigmawechsel in der Rezeption der DDR-Literatur: von totalitarismustheoretisch zu konvergenztheoretisch beeinflußten Deutungsmustern ............................. 1

2. Mythos Bitterfeld: Synchronisierung von Politökonomie, Kulturpolitik und Literatur . . . . . . . . . . . . . . . . . . . . . . 6

3. Periodisierung der Geschichte der Industrieliteratur in der literaturwissenschaftlichen Forschung. . . . . . . . . . . . . . 13

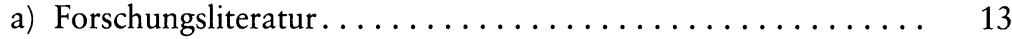

b) Von Trümmerlyrik und Aufbaulied zum Bitterfelder Weg...... 15

c) Von der Arbeiterliteratur zur Literatur der Planer und Leiter .... . 20

4. Konzeption der Untersuchung. .................... 27

a) Industrieliteratur in der ,Übergangsgesellschaft . . . . . . . . . 27

b) Problemstellung und Gliederung der Untersuchung ....... 36

II.Aufbauliteratur der vierziger und frühen fünfziger Jahre: Literatur der Arbeiterklasse oder Sprachrohr der Partei?.................

1. Literaturpolitik zwischen antifaschistisch-demokratischem Bündnis, revolutionärem Anspruch und Propaganda für den Plan`? . . . . . . . .

a) Antifaschistisch-demokratische Literaturpolitik............

b) Sozialistische Transformationsstrategien zwischen Zentralismus und Basis-Initiative . . .................... 44

c) >Aufbau aus eigener Kraft $<$ und PPropaganda für den Plan`...... 48

2. Trümmerlyrik und Aufbaulied: Die Werktätigen arbeiten ....... 56

3. Personenkult und Partei-Panegyrik: Die Partei lenkt. .......... 67

4. Harmonisierung der Widersprüche zwischen Arbeiterklasse und SED

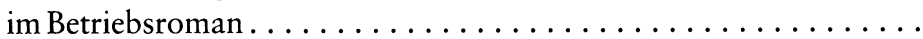

a) Gesellschaftliche und literarische Funktion der $\mathrm{Al}$ tivistenbewegung ................................ 79

b) Der Held der Arbeit und das Proletariat . ............. 83

c) Der Held der Arbeit und die Funktionärshierarchie........ 87

d) Konfliktlösung durch Personalisierung systembedingter Wider-

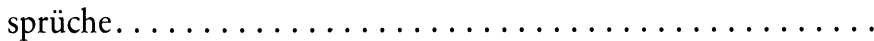

III.»Schreibt die Wabrheit! « - Veränderung der literarischen Darstellungsperspektive im Zeichen des Neuen Kurses und der Kritik an Schematis-

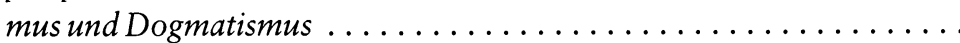


1. Der $>$ Tag $\mathrm{X}<$ : kontroverse Deutung der Ereignisse . . . . . . . . . . 98

2. Der 17. Juni als Thema der DDR-Literatur. . . . . . . . . . . . . . 104

3. Kritik an 'Schematismus und Schönfärberei< . . . . . . . . . . . . . . 109

4. Von der Kritik am Schematismus zur Kritik an Dogmatismus und Stalinismus. . . . . . . . . . . . . . . . . . . . . .

5. Kampagne gegen den Revisionismus und Konzeption des Bitterfelder

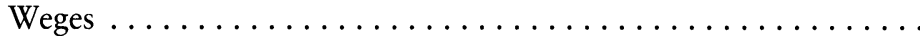

IV.Arbeiterliteratur im Umkreis des dialektischen Theaters und des Bitterfelder Weges: verstärkte Reflexion gesellschaftlicher Widersprüche aus proletarischer Sicht und Hoffnung auf deren technokratische Lösbarkeit. . .

1. Die Dramaturgie des dialektischen Theaters und die Widersprüche der $>$ Übergangsgesellschaft $\_. . \ldots \ldots \ldots \ldots \ldots \ldots \ldots \ldots \ldots$

2. Brechts und Müllers Revolutionsdramen: zwischen Rätedemokratie und Parteidiktatur . . . . . . . . . . . . . . . . . . . .

3. Krisen im ökonomischen Transformationsprozeß als zentrales Thema der Produktionsstücke des dialektischen Theaters. . . . . . . . . .

a) Hartmut Langes Fleischbüchsen-Dialektik: die Arbeiter und der materielle Anreiz . . . . . . . . . . . . . . . . . . . . . . 150

b) Heiner Müller: der Held der Arbeit als Lohndrücker . . . . . . . . . . .

c) Peter Hacks: die Sorgen mit dem System materieller Anreize und die Macht von Technik und Liebe. . . . . . . . . . . . . . . . . . . . 160

4. Exkurs: Antizipation der künftigen Gesellschaft in der Landliteratur. .

5. Interessengegensätze zwischen Arbeitern und Planern und Leitern und deren vermeintliche Aufhebung durch den industriellen Fortschritt .............................

V.Verdrängung der Arbeiterliteratur durch eine Literatur der Planer und Leiter unter dem Eindruck des >Neuen ökonomischen Systems und der ,Wissenschaftlich-technischen Revolution................

1. Literaturpolitischer Kurswechsel im Zeichen der ČSSR-Krise und die

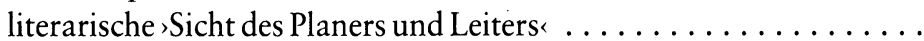

2. Aufhebung der Klassengegensätze durch den >Aufstieg der Arbeiterklasse als Thema der Literatur . . . . . . . . . . . . . . . . . . . . . .

3. Ablösung von Konflikten zwischen Arbeitern und Funktionären durch technokratische Konflikte auf Leitungsebene . . . . . . . . . . . a) Literatur der Planer und Leiter: Varianten eines neuen Genres der Industrieliteratur. . . . . . . . . . . . . . . . . . . 211

b) Konfliktlage im Betrieb: Optimierung contra Betriebsegoismus. . .

c) Konfliktlage im Planungsstab: auf der Suche nach der >optimalen Variante ............................. 
4. 'Sicht des Planers und Leiters` und dialektisches Theater: neuerliches Aufbrechen verdrängter Antagonismen unter dem Eindruck des >Prager Frühlings $\ldots \ldots \ldots \ldots \ldots \ldots \ldots \ldots \ldots \ldots \ldots \ldots \ldots \ldots \ldots \ldots \ldots$

5. Kafka-Konferenz und Entfremdungsdebatte: Literarische Diskussion als Ersatzöffentlichkeit für die Erörterung tabuisierter Widersprüche

VI.Das Scheitern der Illusion von der sozialistischen Menschengemeinschaft und die kritisch-mittelständische Variante der Literatur der Pla-

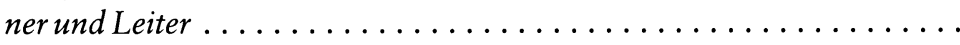

1. Nach dem VIII. Parteitag der SED 1971: 'Erhöhung des materiellen und kulturellen Lebensniveaus des Volkes`als `neue ökonomische Hauptaufgabe ........................

2. 'Reideologisierung durch >offenen Meinungsstreit $\triangleleft$ die Aporien affirmativer Dialektik .

3. Literarische Kontroverse um das Verhältnis von Individuum und Gesellschaft zwischen Entfremdung und Harmonisierung . . . . . . .

4. Ende des Bitterfelder Weges: Literaturpolitik zwischen 'Liberalisie-

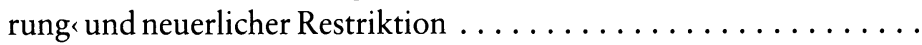

5. Von der sicht des Planers und Leiters zur Darstellung des Alltagsund Arbeitslebens aus dem Blickwinkel eines `neuen Mittelstandes‘ . .

6. Industrieliteratur zwischen den Klassen: die nivellierte Mittelstandsgesellschaft als regressive Utopie im real existierenden Sozialismus . . 286

a) Rückzug von der $`$ Königsebene $\ldots \ldots \ldots \ldots \ldots \ldots \ldots \ldots \ldots$

b) Mittelständische Existenz als idealer Kompromiß? . . . . . . . . 290

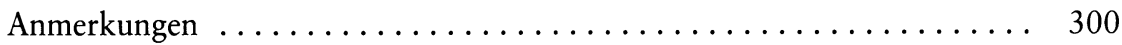

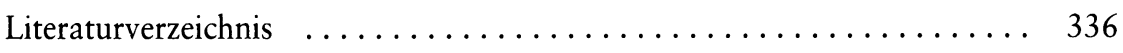

Personenregister $\ldots \ldots \ldots \ldots \ldots \ldots \ldots \ldots \ldots \ldots \ldots \ldots \ldots \ldots$ 